\title{
China's metal intensity in comparative perspective
}

\author{
Huw McKay, Yu Sheng and Ligang Song
}

\section{Introduction}

This chapter has two aims. The first is to reinvigorate the theoretical field that relates economic development to metal usage, which has been lying fallow for considerable time. The second is to shed light on China's future path of ferrous metal demand by referencing the experience of relevant peers over the entire course of the industrialisation process.

In the past decade, a great deal of effort has gone into long-run forecasting projects in the realm of diet (FAO 2002, 2006), agriculture, food supply and water (Bruinsma 2009), energy (McKibbin 2006), carbon emissions (Garnaut et al. 2008; UNDP 2010) and automobiles (IMF 2005a). Long-run metal demand has surprisingly been neglected. This neglect is particularly surprising given that metals' prices have risen so dramatically in real and nominal terms since 2003. The commodity price boom of the 1970s, which brought issues of resource security to the fore, spawned a proliferation of long-run forecasting projects in the metals arena. Beginning with the pioneering work of the International Iron and Steel Institute (1972) and Malenbaum (1973, 1975), which introduced and popularised the intensity of use curve, a number of studies sought to project the demand for metals in the longer run. Two of the best-known works are Leontief et al. (1983) ${ }^{1}$ and Malenbaum (1978).

In this study, we seek to contribute to the broader discussion by employing a richer set of macroeconomic data than that employed in earlier empirical studies, in addition to providing a projection for China's ferrous metal demand to 2030.

This chapter takes as a starting point the observation that the style of development-expressed in differing industrial structures, household consumption patterns, urbanisation paths and levels of openness to trade and investment - matters a great deal for metals. Since countries achieve economic growth with different mixtures of these factors over the short and long run-

1 One of Leontief's co-authors, Ira Sohn, later wrote a second paper (Sohn 2006:Table 9) scrutinising the published forecasts for the year 2000 , finding that all the projections were significant overestimates. 
reflecting comparative advantage or politico-strategic bias-empirical studies in the field seeking generality should recognise that the varied relationship between gross domestic product (GDP) per capita and metal consumption is reflecting these differences and broaden the boundaries of their empirical studies accordingly. Our firm belief is that the relationship between metal use and standard macroeconomic benchmarks is complex and idiosyncratic. The fact that this study accommodates differences across countries is a major advance on previous work. Further, if we wish to claim any generality for our findings, we have met a severe test if we are able to explain the Chinese case - which in the past has confounded expectations drawn from cross-country analysis (for example, IMF 2005b).

We begin by summarising the existing literature on the association between development level and metal intensity and explaining where our approach is different. The intensity-of-use framework, the bottom-up approach applying input-output tables and the 'Kuznets curve for steel' (the KCS, an inverted 'U'shaped curve in steel use per capita and income per capita space), which we introduce, do not automatically translate into neat forecasting frameworks. A sound model of metal demand, whether it is focussed on metals demand per person or per unit of economic output, must simultaneously capture flow, stock, cyclical and developmental/structural influences. Although incorporating all of these variables into a model is a formidable task, the attempt to do so will increase our understanding of the relationship between metal demand and economic development.

The chapter then moves on to discuss the China's demand for metals in particular. It has been noted previously that China's post-1978 history of ferrous metal use has many similarities with the Korean experience (Garnaut and Song 2006; McKay 2008; McKay and Song 2009). Will China continue to follow a path such as Korea's - a nation in which metal intensity of economic activity has remained high for a sustained period; or will the metal intensity of growth only remain high while China is a middle income country en route to the current resting place of the European economies and their offshoots? Will it eventually sit on the more metal-intensive side of the high-income cohort, in a similar place to where Japan resides? These questions are of central importance to China's longrun economic strategy and performance.

A fundamental conclusion of this chapter is that China is unlikely to continue to closely follow the Korean path once it moves deeper into middle-income status. This is due to our contention that China will be compelled to alter its mode of economic growth. China's current reliance on heavy industry, investment vis-avis consumption and high degrees of export orientation will have to be altered if it is to successfully navigate the next phase of its development (McKay and Song 2009). As a consequence, China's final path is likely to emulate certain 
aspects of the experiences of North America, the Commonwealth of Independent States (CIS), Western Europe, Japan and emerging Asia, rather than merely reflecting the course followed by one specific jurisdiction.

\section{The KCS and related theories}

\section{Extant theory and our extension}

Before 1993, the literature on metal usage was divided into two distinct schools: the consumer preference school that pioneered intensity-of-use (IU) analysis, and the leapfrogging school. The consumer preference school argued that IU (defined as the volume of metal consumed per unit of output) increased in low-income economies over time as demand for durable goods created derived demand for metals (International Iron and Steel Institute 1972; Malenbaum 1973). In this view of the world, as economies make the transition towards industrialised status, the consumption basket progressively shifts towards services such as health, education and recreation, at the expense of the metalintensive durable goods market. Thus the development of consumer preferences with rising incomes creates an inverted ' $U$ '-shaped IU curve with a definable turning point.

The leapfrogging school argued that the ability of low-income economies to skip whole generations of technologies gave a downward bias to IU over time (Hwang and Tilton 1990). Essentially, the leapfrogging school argued that a low-income economy's ability to import technology could transplant it to the same point on the hypothesised IU schedule as an advanced economy; or, alternatively, they were able to navigate to lower IU schedules relative to those that previous generations of industrial countries had inhabited at equivalent income levels. The implication was that a low-income economy was just as likely to see a decline in its IU as it moved towards middle-income status, rather than see the rise assumed by the consumer preference school.

The difference between the two schools is best understood by reference to a diagram (Figure 5.1). The leapfrogging school argues that the underlying tendency for low-income economies is to move onto lower IU schedules as they import more advanced technologies (a shift from A on IU2 to B on IU3) or to be conceived immaculately beyond the turning point of the IU schedule, where the parabola is downward sloping. Their adversaries argued that the underlying tendency for low-income economies was to transit along the upward-sloping portion of a single parabola, or in extreme instances to move onto higher IU schedules, as their citizens consumed more sophisticated goods and services (a shift from $\mathrm{A}$ on $\mathrm{IU}_{2}$ to $\mathrm{C}$ on $\mathrm{IU} 1$ ). 
Figure 5.1 Competing theories of metal intensity

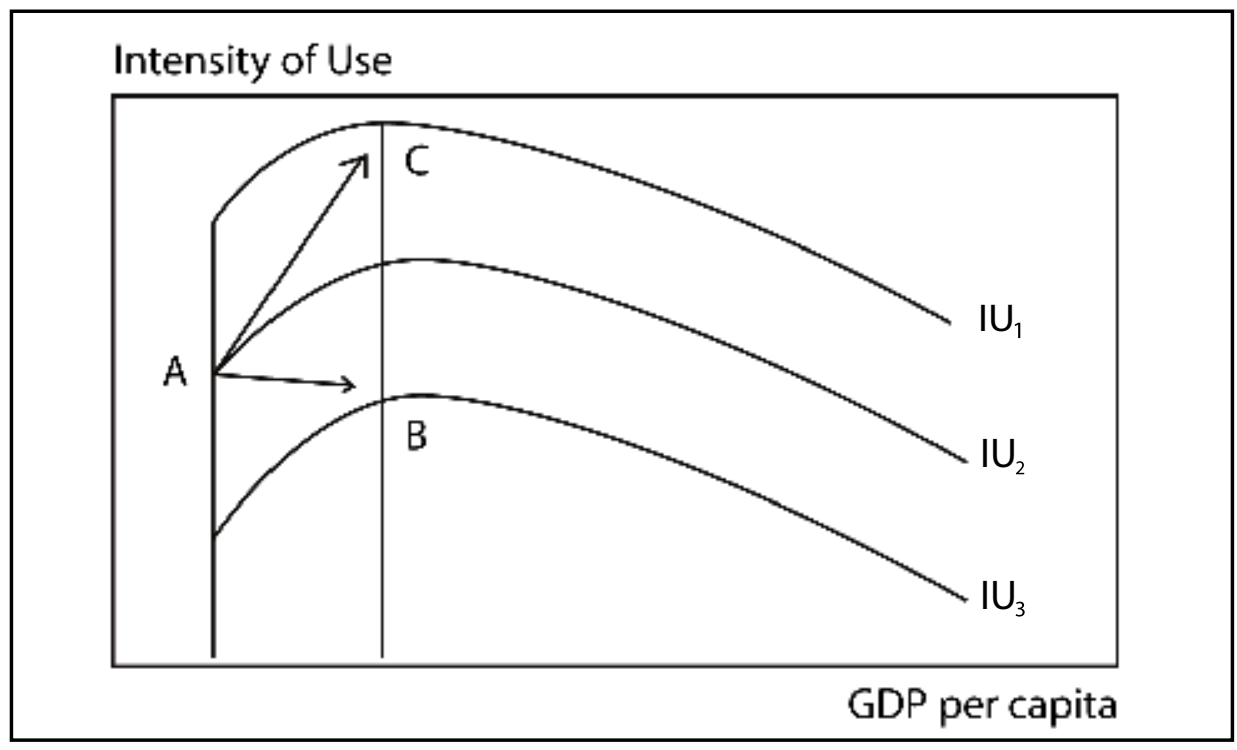

Source: Authors' adaptation of Figure 1 in Hwang, K. H. and Tilton, J. E. 1990, 'Leapfrogging, consumer preferences, international trade and the intensity of metal use in less developed countries', Resources Policy, September, p. 211.

A synthesis was achieved by the work of Lohani and Tilton (1993). They argued that there was partial truth in the teachings of both schools that could be reconciled into a single theory by a relatively simple empirical test. Building on the implications of Hwang and Tilton (1990), Lohani and Tilton studied changes in IU of a cross-section of low-income economies between 1977 and 1988 to test the extant theories and the viability of a synthesis. ${ }^{2}$

Their hypothesis was that IU in the low-income economies was linearly related to income per capita (change in purchasing power and consumption patterns) and time (change in the technological frontier). If the extreme version of the leapfrogging school was correct, the coefficients derived from their crosssectional regression should have been zero for income per capita and negatively related to position on the time trend. If the extreme version of the consumer preference school was correct, the coefficients should have been zero for the time trend and positively related to income per capita. The synthesis would see a positively sign on the coefficient for income per capita and a negative sign on the coefficient for the time trend.

2 Lohani and Tilton assumed a linear relationship for their test, as their sample included only countries gauged to be on the upward-sloping segment of the IU schedule. Note that they were not testing the empirical robustness of the IU schedule itself, which is of course non-linear. Therefore they had nothing to say about the turning point of the IU schedule, which is naturally an important consideration of this chapter. 
The result was that the synthesis view carried the day. More specifically, the authors indicated that a real income growth rate of approximately 1 per cent per annum was required to keep IU stable against the underlying gravity of the leapfrogging phenomenon. Therefore, low-income countries achieving strong rates of economic growth will see a rising IU, but those that are stagnating will see their IU fall due to technological change, or other factors that are captured by the time trend. ${ }^{3}$

These findings reconciled the debate between the opposing schools. The authors noted, however, that their test left about half of the variation in IU across the sample unexplained. The current study extends the analysis in a number of ways as an aid to preparing a long-run projection of China's steel demand.

First, we empirically verify not the IU schedule itself - which measures metal usage per unit of output at various levels of per capita income-but the Kuznets curve for steel (the KCS), which is scaled by population. Our reason for deciding to move away from the IU framework is that we see the KCS as a summary development metric that will stand alongside other measures of absolute and relative living standards - and these measures are invariably expressed in per capita terms. Using population as the denominator and steel consumption as the numerator of our key ratio also has the benefit of couching the KCS as a demandside concept, whereas the IU framework is a product of the supply side.

Beyond verifying the existence of the KCS, we estimate its turning point in income per capita terms. Second, we use the early and middle industrialisation phases of currently middle and high-income economies to inform the analysis, not just the low-income economies of today. Third, we use long time-series data at five-yearly intervals, rather than a contemporary cross-section from a selection of economies at various development levels. We thereby avoid the problems inherent with cross-sectional analysis, particularly where there are data constraints (McKay 2008). ${ }^{4}$ Finally, we broaden our empirical analysis to incorporate macroeconomic variables such as investment propensity,

\footnotetext{
3 Given the leapfrogging phenomenon relies heavily on foreign capital flow, and economies that do not attract the interest of foreign investors tend to be slow growing, it is arguable whether leapfrogging is a terribly strong downward force on IU in poorly performed jurisdictions. Indeed, a shortage of capital will limit the investment share of GDP in these economies, and if investment efficiency is low (as the absence of foreign investors would attest both ex ante and ex post) then income per capita will expand sluggishly, if at all. Conversely, an economy absorbing large amounts of foreign investment will face a much higher than average drag on its IU from the leapfrogging phenomenon. The virtuous relationship between the availability of investment funds, the rising investment share that accommodates it and the rising efficiency of investment as improving technology replaces the old predict, however, a rapid ascent in income per capita that more than offsets the leapfrogging drag on IU. The Korean example is a classic case (Hwang and Tilton 1993).

4 While cross-sectional metal intensity data of recent vintage are available for a wide variety of countries at various states of engagement with an industrial strategy, using these data alone has the potential to be highly misleading. A focus on comparative time-series data is crucial to define the path from A (entry) to B (peak) to $\mathrm{C}$ (maturity). Cross-sections can help with this task, but they can easily mislead rather than guide. The
} 
urbanisation rates, openness to trade and automobile penetration. We apply this enhanced data-set in a simultaneous equation system, the estimation of which is intended to capture the impact of those key variables on aggregate demand. This allows us to test specifically whether the synthesis view of the changing relationship between economic development and IU holds over time and across countries and regions.

Before proceeding to a discussion of the empirical methodology and the data, it is instructive to consider the IU framework as a simple series of equations and identities. Following Etheridge (1981) and Hwang and Tilton (1990), and where $m=$ level of metal consumption, $I U=$ metal use per unit of output, $Y=$ GDP, $N$ $=$ population, $S_{i}=$ sector $i$ 's share in $Y$ and $i_{i}=$ metal use in output of sector $i$, we have Equation 5.1.

\section{Equation 5.1}

$m \equiv I U * \frac{Y}{N} * N$

Dividing through by $\mathrm{N}$ to cast in per capita terms gives Equation 5.2.

\section{Equation $\mathbf{5 . 2}$}

$$
\frac{m}{N} \equiv I U * \frac{Y}{N}
$$

Going further, we have Equations 5.3 and 5.4.

\section{Equation 5.3}

$$
I U=\frac{m}{Y}
$$

\section{Equation $\mathbf{5 . 4}$}

$$
\frac{m}{Y}=\sum\left(\frac{S_{i}}{Y} * \frac{i_{i}}{S_{i}}\right)
$$

So, $\frac{m}{N}$, our core focus, depends on income per capita and IU, which in turn is a function of the sectoral composition of economic activity with respect to metals.

\footnotetext{
difficulty is that while a cross-section is able to define states of nature at $\mathrm{A}$ and $\mathrm{C}$, the path between these two states might be hidden, and B identified erroneously, if the sample is imperfect. This illustration is not to be confused with the exercise in the text centred on Figure 5.1.
} 
Extending to an open economy, allowing for technological change and dividing $Y$ into its constituent parts yields Equation 5.5.

\section{Equation $\mathbf{5 . 5}$}

$I U=f\left(D D_{I U}, E X P_{I U}, I M P_{I U}, t\right)$

In Equation 5.5, $D D$ is domestic demand, EXP and $I M P$ are exports and imports respectively and $t$ is the prevailing state of technology. ${ }^{5}$

Therefore, metal demand can be altered by a change in income per capita, a change in domestic demand that is occasioned by changes in industrial structure (inter-sectoral and/or intra-sectoral) and a change in the nature of a country's international trade. A change in $I U$ could still be achieved in the absence of structural change or income per capita gains through the mechanism of technological change. ${ }^{6}$ Following the leapfrogging school, we assume $t$ is negatively related to $I U^{7}$

\section{'Kuznets curves' as development metrics and some methodological considerations}

The 'Kuznets curve' — an inverse 'U'-shaped curve relating income distribution to income per capita - was first advanced by Kuznets (1955). The evidence for this original Kuznets curve was some patchy time series for a group of industrial countries (the United States, the United Kingdom and Germany/Prussia/ Saxony) and single observations of a few countries at a spread of lower-income levels from Latin America and South Asia. ${ }^{8}$ The inverted ' $U$ ' was formed by this mixture of time-series and cross-sectional data. The lower-income economies provided the hump in the hypothesised curve, 'corroborating' the patchy timeseries evidence.

Subsequent experience of East Asian development trajectories in the quartercentury after World War II, in which inequality was reduced between the

5 Inventories are ignored here as they are assumed to be neutral for economic structure.

6 A change in relative prices could also bring about a change in IU. If heavy industry is a strategic sector under a developmental state, it is likely that factor prices (for instance, land, labour, energy, capital) will be suppressed to assist the sector. The removal of such distortions will clearly impact on IU. This is particularly pertinent in the situation of China (Huang and Tao 2010).

7 This framework obviously lends itself to input-output (I-O) analysis, in which metal use coefficients can be estimated and applied. This technique is entirely appropriate in industrialised economies with relatively stable structures. Given the inherent delay in the publication of detailed I-O tables, however, and their fiveyear periodicity, it is unlikely that they would provide an accurate 'leaping-off point' for assessing the IU situation in a country developing as rapidly as China.

8 Kuznets used data from India (1949-50), Ceylon (now Sri Lanka; 1950) and Puerto Rico (1948). 
low and middle-income stages of development, has shown that the Latin American and South Asian paths observed by Kuznets are idiosyncratic rather than general. The two regions followed development models that encouraged the super-normal growth of a rent-seeking elite, with predictable outcomes for income distribution. Therefore, the original Kuznets curve is a cautionary tale for scholars of development looking to cross-sectional data for predictive relationships.

In the metals sphere, a contemporaneous cross-section of countries at various income levels can be readily assembled to show an apparent Kuznets-type relationship. The apex of the hump in the curve relating steel demand per person to per capita income is provided by two medium-sized upper middleincome North Asian economies: Korea and Taiwan. They are both relatively new entrants to industrialisation with their engagement occurring within the past half-century. Are these economies typical or atypical? This judgment could validate or invalidate the cross-section as representative, as we do not have readily available middle-income alternatives to substitute for them.

Preliminary investigations by McKay (2008) document the existence of a KCS relationship in a long time series of steel use per capita in the United States. The empirical evidence in favour of a Kuznets relationship in the long-run steel demand per capita in the United States is strong. The finding that steel use per capita in the United States during the twentieth century followed an inverted ' $U$ ' shape 'corroborates' the cross-sectional 'evidence' available from a scatter plot, indicating that the Kuznets framework could be applicable to the entire field of metal demand. Development is, however, a complex process conditioning a rich variety of urbanisation processes, investment approaches and sectoral transformations (and in China's case, ownership transformations [Garnaut et al. 2006] and imperfections in the markets for resources), differing approaches to international trade, foreign investment, financial systems, institutional reform, and so on. It is therefore potentially misleading to reduce an economy's development process to an aerial view of a high-growth phase following initial engagement with industrialisation, followed by a deceleration as the ability to benefit from convergence of productivity levels is reduced as it approaches the frontier. Rather, given the observed heterogeneity of 'pathways from the periphery' (Haggard 1990), it is necessary to build a system that can account for these differences.

In short, while the shortcut of generalising from a narrow potentially unrepresentative sample is tempting, it is not appropriate. What is needed is an approach that allows for national deviations from the average path within a consistent aggregate framework. Our approach, therefore, is to estimate the aggregate KCS relationship and its underlying determinants in a simultaneous procedure. 


\section{Model specification and estimation strategy}

\section{Model specification}

To examine the potential Kuznets relationship between long-term steel demand per capita and economic development, we follow McKay (2008) by assuming that steel demand per capita is a function of income per capita, its square term and a control vector (Equation 5.6).

\section{Equation 5.6}

lncsteel $_{i t}=\beta_{0}+\beta_{1} \operatorname{lncgdp_{it}}+\beta_{2} \ln c g d p_{-} s q_{i t}+\gamma Z_{i t}+\varepsilon_{i t}$

In Equation 5.6, lncsteel $_{\text {it }}$ denotes the logarithm of annual steel consumption per capita and $\operatorname{lncgdp_{it}}$ and $\ln c g d p_{-} s q_{i t}$ the logarithm of GDP per capita and its square term of country $i$ at time $t$ respectively. $Z_{i t}=\left(\operatorname{lnccar}_{i t}^{1}, \mathrm{t}\right)$ is the control vector, accounting for the impact of automobile penetration (defined as the logarithm of the number of passenger cars per 1000 people) and technological progress (defined as the time trend). Thus, the null hypothesis for the Kuznets relationship to be robust is that the estimated coefficients in front of the logarithm of GDP per capita and its square term should be positive and negative in sign, respectively, and statistically significant. Additionally, a negative and statistically significant coefficient assigned to the time trend will provide support for the leapfrogging hypothesis. The degree of automobile penetration is a proxy variable for the consumer preference hypothesis. A positive coefficient is expected here.

This is a major advance on the work of Lohani and Tilton (1993). Positioned in this fashion, our test can offer a comprehensive update and extension of the synthesis view of the relationship between economic development and IU. In addition, this approach can infer the turning point in the KCS - something that is beyond a single equation linear system. It also has some utility as a projection model that we later apply to the question of China's future metal demand.

Equation 5.6 can be directly estimated by various methods, but the results might not be economically robust in isolation. This is because a parsimonious single equation exercise potentially violates the empirical reality that the nature of the industrialisation process is just as important as the development level in determining the path of long-term steel demand per capita. To control for this factor, we choose a simultaneous estimation of three equations (Equations 5.6, 5.7 and 5.8), with steel use per capita, GDP per capita and its squared term, 
respectively, serving as dependent variables. The estimation utilises five-year panel data - essentially smoothed long time-series - for a representative sample of the global economy. The data cover 14 countries and regions from as early as 1890 until 2008.

The variety of local conditions prevailing at the entry point into industrialisation strategies, the different states of local and global technological attainment at each 'time stamp', divergent comparative advantages and a diversity of institutional approaches to the development task have generated substantially different degrees of steel demand per capita at similar income per capita levels. Therefore, in the analysis of the KCS, GDP per capita can be plausibly treated as an intermediate variable that is jointly determined by the broad parameters that characterise a nation's mode of economic development. These factors include the urbanisation process, investment propensity, motorisation and the degree of openness to trade. While these factors are endogenous to the style of economic development adopted, econometrically speaking they are exogenous determinants of GDP per capita in our model.

Equations 5.7 and 5.8 complete the system required for the test.

\section{Equation 5.7}

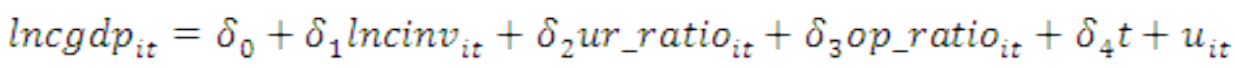

\section{Equation 5.8}

$$
\operatorname{lncgdp_{-}sq_{it}}=\varphi_{0}+\varphi_{1} \operatorname{lncinv}_{i t}+\varphi_{2} u r_{-} \text {ratio }_{i t}+\varphi_{3} \text { op } \text { ratio }_{i t}+\varphi_{4} t+v_{i t}
$$

In both equations, $\operatorname{lncin} v_{i t}$ is the logarithm of total investment per capita, ${ }^{9} \mathrm{ur}_{-}$ratio $_{i t}$ is the urbanisation rate (defined urban population share of the total population) and $o p_{-}$ratio $_{i t}$ is an openness to trade index (defined as exports plus imports over GDP).

Equations 5.6-8 are estimated using the simultaneous equation method. There are two econometric problems to be solved before an unbiased and consistent estimation can be reached.

First, since we use panel data for the exercise, the country-specific effect needs to be eliminated. If there are time-invariant country-specific unobserved factors determining the dependent variable (that is, steel demand per capita) that are

9 We use investment per capita rather than the more usual choice of the investment share of GDP. We do this because while a developing economy might have a high investment share, it is most unlikely to have a large capital stock relative to its workforce. This enables us to capture a prolonged process of capital deepening that will not necessarily be captured by the investment share (especially where the efficiency of investment improves over time) as well as the importance of depreciation expenditures at higher levels of development. 
also correlated with the independent variables (that is, GDP per capita), the estimated coefficients could be either over or underestimated. To deal with this problem, we take the first difference for all variables and use Equations 5.6', $5.7^{\prime}$ and $5.8^{\prime}$.

\section{Equation 5.6'}

dlncsteel $_{i t}=\gamma_{0}+\beta_{1} d \operatorname{lncg} d p_{i t}+\beta_{2} d \operatorname{lncg} d p_{-} s q_{i t}+\gamma_{1} d \operatorname{lnccar} r_{i t}+d \varepsilon_{i t}$

\section{Equation 5.7'}

$$
\text { dlncgdp } i t=\delta_{4}+\delta_{1} d l n c i n v_{i t}+\delta_{2} d u r_{-} \text {ratio }_{i t}+\delta_{3} \text { dop_ratio } i t+d u_{i t}
$$

\section{Equation 5.8'}

$d l n c g d p_{-} s q_{i t}=\varphi_{4}+\varphi_{1} d l n c i n v_{i t}+\varphi_{2} d u r_{-}$ratio $_{i t}+\varphi_{3} d o p_{-}$ratio $i t+d v_{i t}$

In all three equations, $d(\cdot)$ represents first differences.

Second, when the simultaneous equation regression technique is adopted, the potential correlation among the residuals across equations introduces the efficiency problem for the estimated coefficients (Zellner 1962). In other words, if we assume that $d \varepsilon_{i t}, d u_{i t}$ and $d v_{i t}$ are independently and identically distributed (as is normally assumed in statistics), the estimated standard error for all coefficients would be biased since $d \varepsilon_{i t}, d u_{i t}$ and $d v_{i t}$ could be correlated through the dependent variables that are correlated across different equations. Thus, the statistical significance of the regression is rendered dubious. To deal with this problem, we use the seemingly unrelated regression (SUR) technique to adjust the covariance matrix in our estimation.

To test the stability of our results, we carried out two robustness checks. On one hand, we substituted the original dependent variables with other development measures (such as electricity consumption, rail freight and shipping vessels all in per capita and logged form). The results did not differ substantially. We also used a variety of econometric techniques. ${ }^{10}$ Once again, the results were consistent in terms of the expected signs and statistical significance of the estimated coefficients.

10 The substitute variables were electricity consumption, rail freight and shipping vessels (all in per capita and logged form). The alternative methods were a dynamic panel regression (with GDP per capita specified as the endogenous variable) and an IV regression (with different model specifications). 


\section{Data description}

The panel data used for this study cover 14 countries and regions between 1890 and 2008. The sample comprises Canada, the United States, Latin America, Africa, European members of the Organisation for Economic Cooperation and Development (OECD), the Commonwealth of Independent States countries (Russia after 1990), the Middle East, India, China, South-East Asia, Oceania, Japan, Korea and Taiwan. To reduce year-to-year fluctuations, we sampled the data at five-year intervals. The regional definitions are consistent with those used by the International Steel Association.

Figure 5.2 Crude steel output per capita of selected economies, 1890-2008

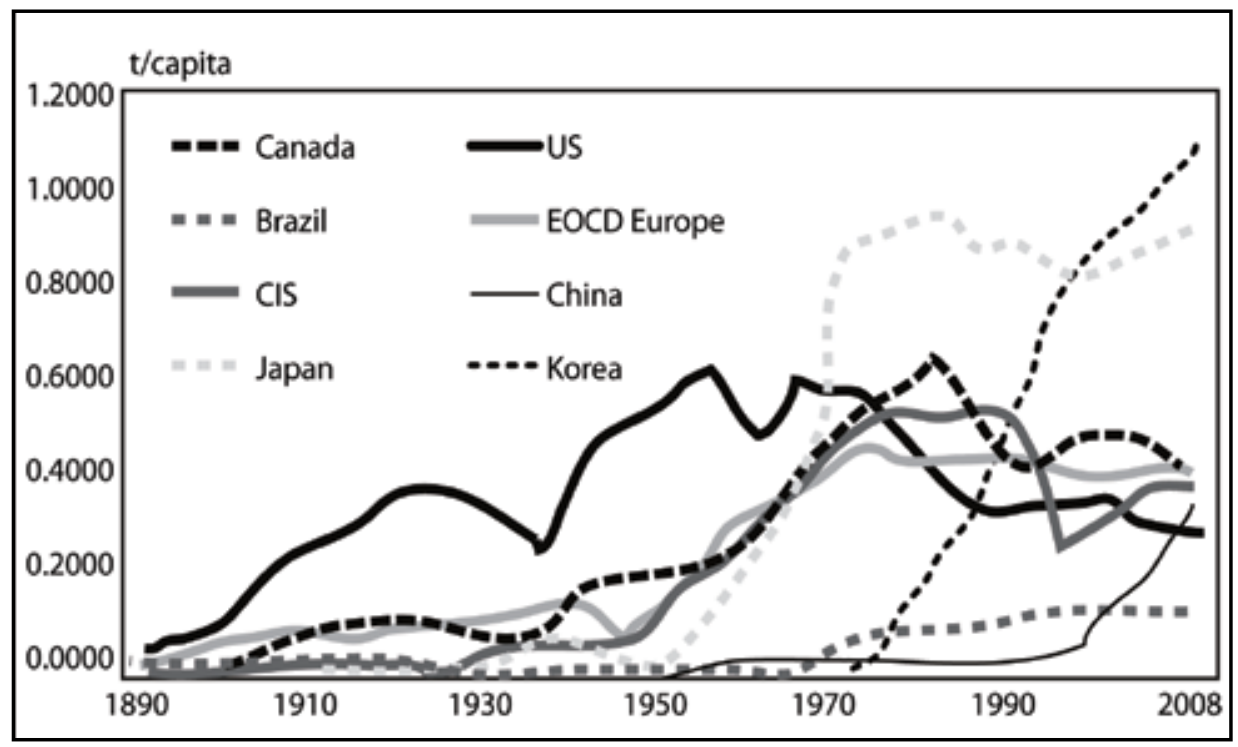

Source: Data from the World Metal Statistics Yearbook, various issues, International Steel Association.

The macroeconomic variables we employ are steel use, GDP, investment, electricity use, private automobile ownership (all scaled by population), openness to trade (scaled by GDP) and the urbanisation rate. The measures of all variables are consistent across countries and over time. Steel use is defined as total crude steel consumption. GDP is measured at 1990 constant price international US dollars. Investment is defined as gross fixed capital formation. The urbanisation rate is the percentage of urban residents in the total population. Openness to trade is defined as exports plus imports over GDP.

The data come from three principal sources. Crude steel production and consumption come from the International Steel Statistics; population data come from Maddison (2003, 2010; the Penn World Table (Centre for International 
Comparisons n.d.) was used for obtaining the national accounts variables and urbanisation rates; and the CHIPs database of the National Bureau of Economic Research (NBER) provided private car registrations per 1000 people, electricity consumption per capita and some other country-specific variables.

There is a clear similarity in terms of the pattern of rising steel output per capita for the United States from the mid 1930s to the end of the Korean War, and for Canada, Europe and the CIS from the 1950s to the 1970s. The experience of Japan from the early 1950s to the 1970s and Korea from the early 1970s to the present day, and China since 2000, are also quite similar (Figure 5.2). While the levels of steel production per capita in the United States and Canada fell steadily after reaching their peaks (thereby tracing an inverted U shape), Europe and the CIS held their peaks for longer.

Japanese steel use per capita has remained steady in the decades after its peak, while Korea is yet to peak, even if the rate of increase has slowed since the 1990s. Japan's and Korea's levels of per capita steel production have reached a point much higher than those reached by other industrialised countries. These levels are thus unprecedented in the Western history of industrialisation. Figure 5.2 also shows that in the case of Japan, the phase of acceleration lasted for about 20 years (1950-70) while the path has been more protracted for Korea at almost 40 years and counting. This illustrates the point made earlier about the unique path of metal consumption in Korea. The question as to what extent the level of per capita steel production of China will rise and how long the phase of acceleration will last is significant and remains to be addressed.

Figure 5.3 illustrates the relationship between steel output per capita and income per capita in the major countries and regions over the long period 1890-2008. The figure presents three features. First, the trajectories of certain countries (especially in East Asia) seem to support the consumer preference view - namely, that steel demand continues to rise along with increases in per capita income. This process is extended even beyond the point where other industrialised countries have reached the peak in their steel intensities. Second, Western economies have demonstrated a pattern of change that is more in support of the leapfrogging view-namely, their steel intensities began to fall after peaking between US\$10 000 and US\$15000 of income per capita. Steel use then stabilises about the US\$20 000 level between one-half and three-quarters of the peak level and thereafter follows a cyclical pattern of change. 
Figure 5.3 Crude steel output and GDP, scaled by population, 1890-2008

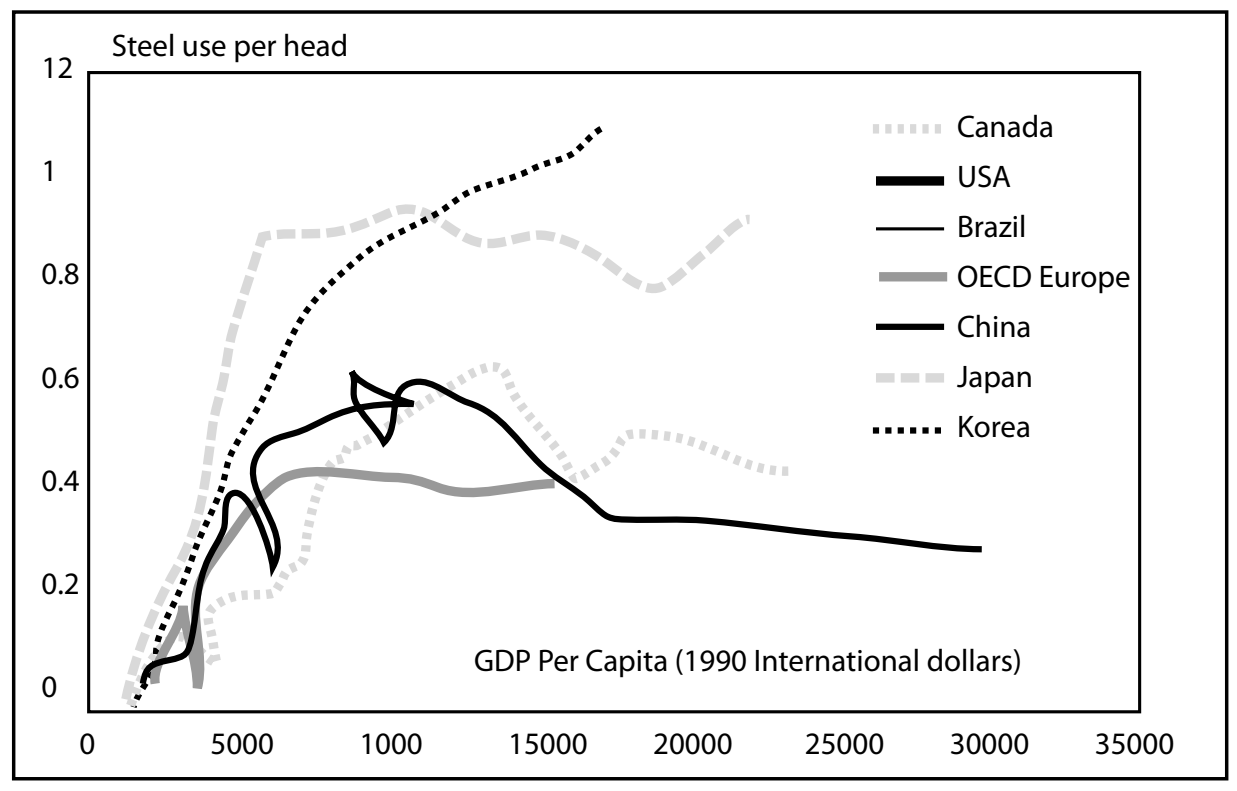

Source: World Metal Statistics Yearbook, various issues, International Steel Association.

These are the basic data that provide the dependent variables for the formal econometric exercise detailed in sections three and four in which we test the validity of the different theories and their synthesis. It is also the context in which the future trajectory of China's steel demand per capita is projected.

Figure 5.4 Urbanisation ratios of selected economies, 1890-2005

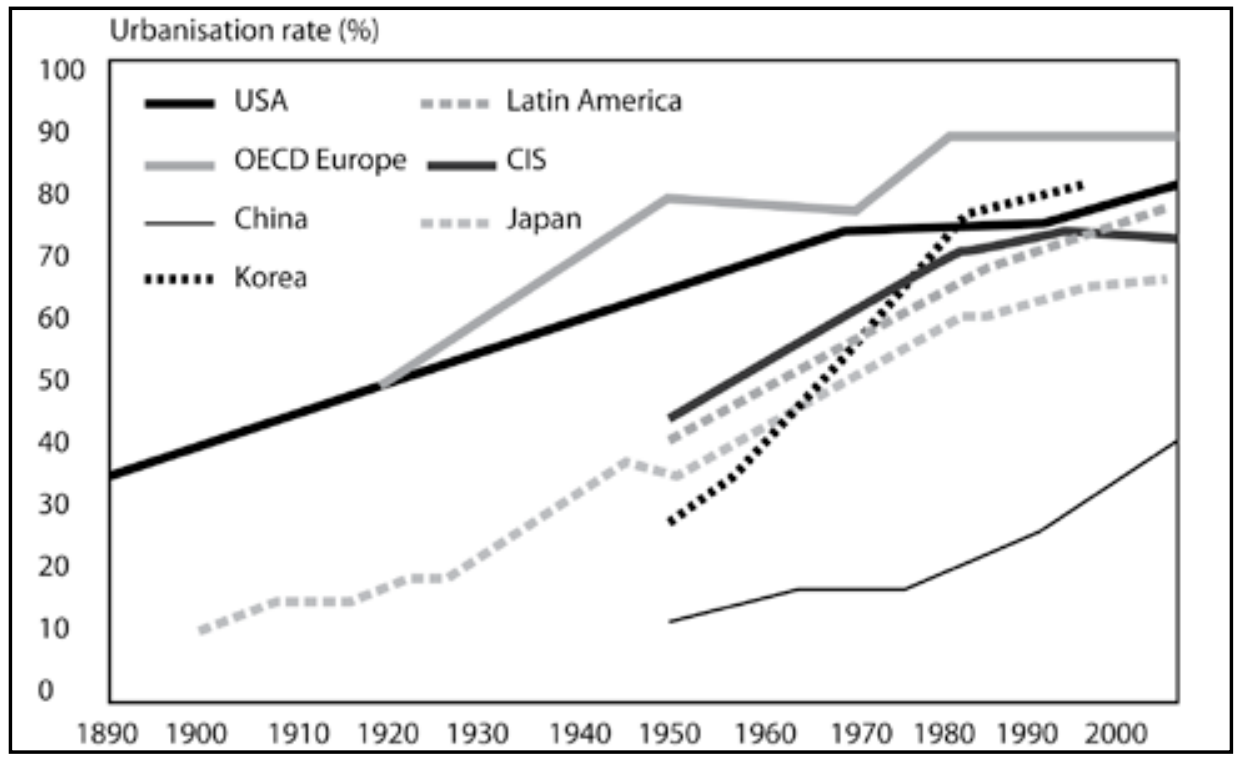

Source: Center for International Comparisons n.d., The Penn World Table,University of Pennsylvania, Philadelphia. 
The difficulty of the modelling task is illustrated with reference to one of the explanatory variables: the urbanisation rate (Figure 5.4). The urbanisation process tends to be associated with rising steel demand per capita as it directly contributes to GDP growth through the well-known Lewisian dynamics of sectoral transfer. It also requires a dwelling and infrastructure-building program to accommodate the population shift. The benefits of agglomeration drive an increase in service sector activity, greater specialisation and the associated productivity gains. Each of these factors generates income growth, which increases effective demand, and so on. As this short description indicates, the urbanisation process is an attractive variable for proponents of the consumer preference view. There is nothing rigid, however, about the relationship between urbanisation and steel use. For example, Brazil's urbanisation ratio is close to 80 per cent, but Brazil has a relatively low level of steel intensity (and income per capita). Brazil also has a rich endowment of ferrous metal resource reserves. At a similar level of urbanisation, Korea's steel intensity is much higher than that of the United States. At a much lower level of urbanisation, China's steel intensity has already surpassed those for the United States and Brazil. China's steel use is converging with that of the CIS, where urbanisation is significantly higher. In the case of Japan, its steel intensity is much higher than that of the United States with a lower level of urbanisation, despite the density of its population and its weak resource endowment (McKay 2008). It is both theoretically and intuitively sound to include urbanisation rates in the empirical test. Yet a quick review of the country-level data highlights the differences between countries in the sample.

\section{Estimation results and projection}

The estimation results from the model presented above capture the interactive relationship between steel consumption per capita, GDP per capita and their common determinants, as summarised in Table 5.1.

The first implication of the test is that the KCS does indeed exist. Our estimation of Equation 5.6' yields results in line with our expectations. As shown in Table 5.1, the coefficients assigned to GDP per capita and its squared term are positive and negative, respectively, and are significant at the 1 per cent level. Further, the motorisation variable also behaves as expected, with a statistically significant positively signed coefficient estimated for the number of automobiles per 1000 people. This corroborates the view that consumer preferences have played an important role in determining steel consumption over time. Generally, the greater the degree of motorisation the higher steel demand per capita is likely to be. The time trend and its square term are significant at the 1 per cent level 
with positive and negative signed coefficients, respectively, correctly signed to corroborate the leapfrogging hypothesis. So, with the consumer preference and leapfrogging views both validated simultaneously, the synthesis view is upheld (Lohani and Tilton 1993) and extended, and a new concept, the KCS (McKay 2008), has been more rigorously identified.

Table 5.1 Major results from simultaneous equation estimation, 1890-2008

\begin{tabular}{|c|c|c|c|c|c|}
\hline \multicolumn{2}{|c|}{ Dependent variable: Insteel } & \multicolumn{2}{|c|}{ Dependent variable: Ingdp } & \multicolumn{2}{|c|}{ Dependent variable: Ingdp_sq } \\
\hline Ingdp & $\begin{array}{l}6.299 * * * \\
(1.325)\end{array}$ & Innewinv & $\begin{array}{l}0.418 * * * \\
(0.056)\end{array}$ & Innewinv & $\begin{array}{l}6.664 * * * \\
(0.959)\end{array}$ \\
\hline Ingdp_sq & $\begin{array}{l}-0.313 * * * \\
(0.078)\end{array}$ & urban_ratio & $\begin{array}{l}0.018 * * * \\
(0.006)\end{array}$ & urban_ratio & $\begin{array}{l}0.233 * * \\
(-0.097)\end{array}$ \\
\hline Lncar & $\begin{array}{l}0.118 * \\
(0.057)\end{array}$ & open_ratio & $\begin{array}{l}-0.001 \\
(0.003)\end{array}$ & open_ratio & $\begin{array}{l}0.001 \\
(0.049)\end{array}$ \\
\hline Time trend & $\begin{array}{l}-0.028 * * * \\
(0.011)\end{array}$ & Time trend & $\begin{array}{l}0.009 * \\
(0.005)\end{array}$ & Time trend & $\begin{array}{l}0.145 * \\
(0.083)\end{array}$ \\
\hline $\begin{array}{l}\text { Time trend } \\
\text { squared }\end{array}$ & - & $\begin{array}{l}\text { Time trend } \\
\text { squared }\end{array}$ & $\begin{array}{l}- \\
-\end{array}$ & $\begin{array}{l}\text { Time trend } \\
\text { squared }\end{array}$ & $\begin{array}{l}- \\
-\end{array}$ \\
\hline Constant & $\begin{array}{l}0.495 * * \\
(0.208)\end{array}$ & Constant & $\begin{array}{l}-0.128 \\
(0.095)\end{array}$ & Constant & $\begin{array}{l}-1.853 \\
(1.609)\end{array}$ \\
\hline $\begin{array}{l}\text { Adjusted } \\
\text { R-squared }\end{array}$ & 0.48 & $\begin{array}{l}\text { Adjusted } \\
\text { R-squared }\end{array}$ & 0.56 & $\begin{array}{l}\text { Adjusted } \\
\text { R-squared }\end{array}$ & 0.52 \\
\hline $\begin{array}{l}\text { Number of } \\
\text { observations }\end{array}$ & 72 & $\begin{array}{l}\text { Number of } \\
\text { observations }\end{array}$ & 72 & $\begin{array}{l}\text { Number of } \\
\text { observations }\end{array}$ & 72 \\
\hline
\end{tabular}

Note: - zero, ${ }^{* * *} \mathrm{p}<0.01,{ }^{* *} \mathrm{p}<0.05,{ }^{*} \mathrm{p}<0.1$. For simplicity, we do not report the estimation results for Equation 5.8, which are available on request from the authors. The numbers in brackets are standard errors.

Source: Authors' own estimations.

Second, while these results are a major upgrade and extension of previous work in the field of metal demand, they do not enable us to proceed directly from Equation $5.6^{\prime}$ to a projection of China's steel demand. Not only has China's steel demand commonly defied attempts to be explained by cross-country data-sets (for example, IMF 2005b), but GDP per capita alone has been shown to be at best a weak predictor of metal usage per capita across all countries. To cast forward, we must also understand that there are many common factors related to the style of industrialisation driving both IU and GDP per capita.

These common factors are well covered by Equations 5.7' and 5.8', in which GDP per capita and its squared term are regressed on investment per capita, the urbanisation rate and the degree of openness to trade. Each of these factors can affect income per capita and metal consumption per capita. It is the combination of these factors that generates the apparent KCS. In our estimation results, not 
only do both investment per capita and urbanisation positively contribute to GDP per capita (at the 1 per cent level), they explain the square term of GDP per capita (positively related and significant at the 1 per cent level). ${ }^{11}$ Thus, when we substitute Equation 5.7' and Equation 5.8' into Equation 5.6', steel consumption is driven by these three factors in addition to proxies for consumer preferences and technological progress.

\section{A projection: China's metal demand and economic development}

The substitution of these stylistic variables back into Equation 5.6' allows us to use the KCS formulation as a projection model without sacrificing national heterogeneity. The data presented above, taken together with the econometric results and a working knowledge of economic history, lead to the conclusion that while a general relationship between development-related macro variables does exist, substantial national variations from the central path are common. This permits many potential degrees of steel demand per capita at a given level of income per capita. While the KCS is a good starting point for the discussion, it is not the end game. We must also take account of the other factors underlying the macroeconomic dynamics, while factoring in how the institutional framework is most likely to evolve over time.

China has defined its own trajectory in these contexts to form a unique economic history. Its future will also be distinctive. China's future demand for metal will borrow from others - such as Korea and Japan, the United States, the CIS and Western Europe - but the outcomes will reflect China's unique characteristics.

Table 5.2 summarises major economic development indicators for China between 1980 and 2008, which helps to outline how rapid growth in income per capita has been achieved. During the past three decades, investment, resource demand and openness to trade have all expanded at rapid rates. The urbanisation rate has been increasing, but at a slower rate, reflecting the institutional constraints imposed by policy. All these factors will contribute to the future course of income per capita and, combined with technological progress and changing consumption preferences, will determine the path of steel consumption per capita in the period ahead.

11 Although the degree of openness to trade is not significant in our model, we keep it in our regression since we think that it is an important control variable from a conceptual perspective. 
China: The Next Twenty Years of Reform and Development

Table 5.2 China's economy and steel demand per capita, 1980-2008

\begin{tabular}{|c|c|c|c|c|c|c|c|}
\hline Year & $\begin{array}{c}\text { Steel } \\
\text { per } \\
\text { capita } \\
\text { (tonne) }\end{array}$ & $\begin{array}{c}\text { GDP per } \\
\text { capita } \\
\text { (1990 } \\
\text { int'l } \\
\text { dollar) }\end{array}$ & $\begin{array}{c}\text { Investment } \\
\text { share }(\%)\end{array}$ & $\begin{array}{l}\text { Openness } \\
\text { to trade } \\
\text { index }(\%)\end{array}$ & $\begin{array}{c}\text { Urbani- } \\
\text { sation } \\
\text { rate } \\
(\%)\end{array}$ & $\begin{array}{l}\text { Electricity } \\
\text { per capita }\end{array}$ & $\begin{array}{c}\text { Passenger } \\
\text { cars } / 1000 \\
\text { people }\end{array}$ \\
\hline 1980 & 0.0435 & 809 & 25.1 & 31.5 & 19.6 & 307 & - \\
\hline 1985 & 0.0555 & 985 & 34.3 & 32.2 & 23 & 374 & 0.3 \\
\hline 1990 & 0.0644 & 1400 & 40.8 & 25.4 & 27.4 & 565 & 0.7 \\
\hline 1995 & 0.0789 & 1754 & 43.6 & 32.2 & 31.4 & 842 & 2.1 \\
\hline 2000 & 0.1002 & 2718 & 37.1 & 41.9 & 35.8 & 1046 & 4.9 \\
\hline 2005 & 0.2716 & 3297 & 51.7 & 67.3 & 40.4 & 1131 & 14.1 \\
\hline 2008 & 0.3752 & 5449 & 54.4 & 69.0 & 44.9 & 2452 & 21.6 \\
\hline $\begin{array}{l}\text { Compound } \\
\text { annual } \\
\text { growth rate } \\
\text { (since } \\
1980 \text { ) }\end{array}$ & $8.0 \%$ & $7.0 \%$ & $2.8 \%$ & $2.8 \%$ & $3.0 \%$ & $7.7 \%$ & \\
\hline $\begin{array}{l}\text { Compound } \\
\text { annual } \\
\text { growth } \\
\text { rate (since } \\
\text { 1990) }\end{array}$ & $10.3 \%$ & $7.8 \%$ & $1.6 \%$ & $5.7 \%$ & $2.8 \%$ & $8.5 \%$ & $20.8 \%$ \\
\hline
\end{tabular}

Source: National Bureau of Statistics (NBS) various years, China Statistical Yearbook, China Statistics Press, Beijing; except for the investment share, which is from World Bank n.d., World Development Indicators, Online database, The World Bank, Washington, DC.

To begin, we present a scenario in which current trends persist through the projection period. Using the current growth rates in investment per capita, urbanisation and openness to trade indexes, (an admittedly naive baseline), we project the relationship between income per capita and metal intensity for China over time (shown in Figure 5.5) with confidence intervals jointly determined by country-specific characteristics and measured as standard deviations. The method used for this projection is not based on the predetermined KCS relationship but on the contributions of our three core development factors related to GDP per capita and steel consumption separately. Based on a 2008 leaping-off point, we assume that all three factors have a constant marginal impact on GDP per capita and steel consumption (obtained from our simultaneous regressions). The sum of these products is then used to generate the forward trajectories of the two series: GDP per capita and steel consumption.

On this basis, our estimate of the GDP per capita level consistent with the turning point of China's own KCS is US\$15 449. Given the fact that China's level of per capita income was US\$5449 in 2008 (Table 5.2), per capita income must almost triple before peak intensity is attained. Chinese GDP per capita grew at a compound rate of 7 per cent between 1980 and 2008. If that rate were sustained, 
China's steel intensity would peak during 2024. If the somewhat faster post1990 pace of 7.8 per cent is used (a rate consistent with GDP per capita more than doubling each decade) then the turning point is reached three years earlier. The central tendency of the projection indicates that peak demand for steel will be in the upper half of a range of $700-800 \mathrm{~kg}$ per capita at this income per capita level. This peak level of demand for steel in China will be higher than the one reached by the United States in the 1950s or Europe, Canada and the CIS in the 1970s. It would, however, be lower than those reached by Japan in the 1980s and by Korea and Taiwan at the present time.

The usual caveats apply to this projection, which is only as good as the chosen time path of the exogenous variables.

Figure 5.5 Projection of steel demand per capita, extrapolating current trends

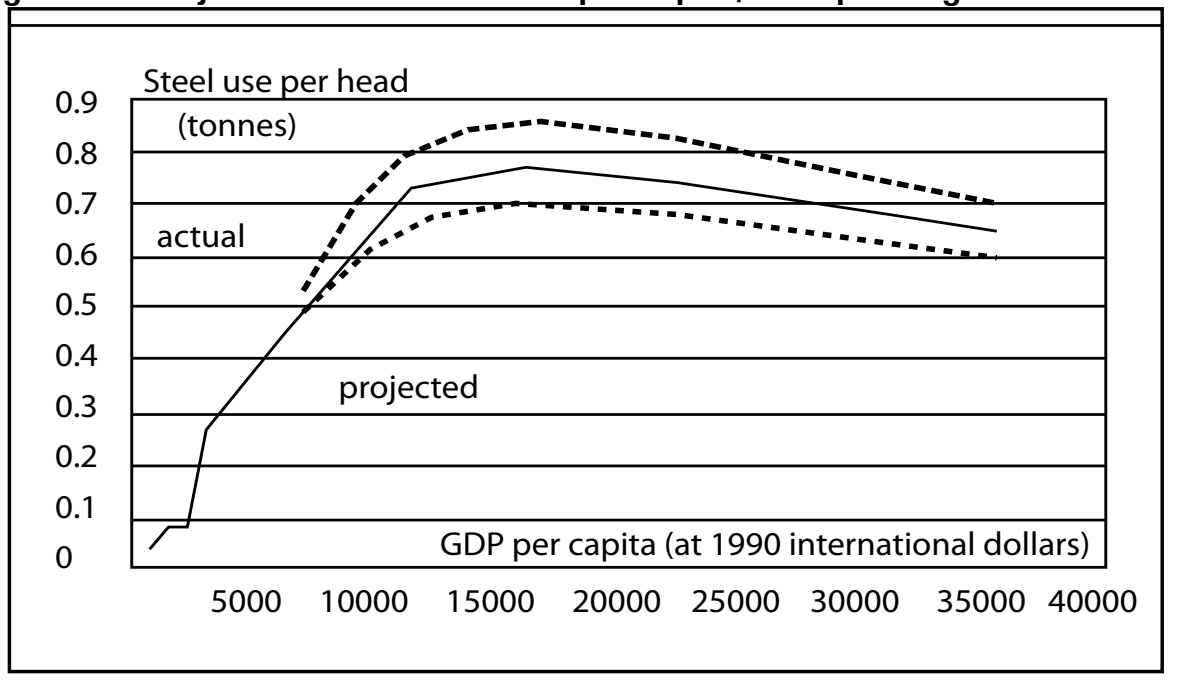

Source: Authors' own projections.

\section{Discussion and critique of the projection}

The projection illustrated in Figure 5.5 is based on the naive assumption that current trends persist into the future. If economic history tells us anything, it is that stasis is the least likely outcome for an economy at China's present stage of development. Table 5.3 shows the forward assumptions utilised in a recent UN report on the future of the Chinese economy (UNDP 2010). The contours of the UN scenario are a decelerating rate of GDP per capita growth, a continuing rise in the urbanisation rate and motorisation that decelerates progressively as 
Chinese levels approach those of high-income economies, a reduced but still high emphasis on secondary industry in overall activity and a peak in steel demand per capita about $630 \mathrm{~kg}$ by 2030 .

Table 5.3 UN projection of China's future development path

\begin{tabular}{|c|c|c|c|c|c|c|}
\hline & 2005 & 2010 & 2020 & 2030 & 2040 & 2050 \\
\hline Urbanisation rate (\%) & 43 & 48 & 56 & 62 & 66 & 70 \\
\hline $\begin{array}{l}\text { Secondary industry } \\
\text { share of GDP }\end{array}$ & 48 & 49 & 48 & 46 & 42 & 38 \\
\hline Cars per 1000 people & 24 & 70 & 190 & 300 & 356 & 400 \\
\hline $\begin{array}{l}\text { Per capita GDP (spliced } \\
\text { to } 1990 \text { int'l dollars)* }^{*}\end{array}$ & 3297 & 4990 & 8868 & 14450 & 22151 & 32079 \\
\hline $\begin{array}{l}\text { GDP growth rate } \\
\text { (decade average) }\end{array}$ & - & 9.5 & 6.6 & 5.5 & 4.5 & 3.5 \\
\hline Population (millions) & 1308 & 1360 & 1450 & 1520 & 1540 & 1500 \\
\hline $\begin{array}{l}\text { GDP per capita growth } \\
\text { rate (decade average)* }\end{array}$ & - & 8.7 & 6.0 & 5.0 & 4.4 & 3.8 \\
\hline $\begin{array}{l}\text { Power generation } \\
\text { Terawatt hours (TWh) } \\
\text { (business as usual) }\end{array}$ & 2494 & 3830 & 6603 & 8880 & 10937 & 12360 \\
\hline $\begin{array}{l}\text { Steel output ( } 100 \\
\text { million tonnes) }\end{array}$ & 3.5 & 5.6 & 8.6 & 9.6 & 9.1 & 8 \\
\hline $\begin{array}{l}\text { Implied steel per capita } \\
\text { (tonnes per capita)* }\end{array}$ & 0.27 & 0.41 & 0.59 & 0.63 & 0.59 & 0.53 \\
\hline
\end{tabular}

* Calculated by the authors from the existing information.

Source: United Nations Development Programme (UNDP) 2010, China Human Development Report 2009/10. China and a sustainable future: towards a low carbon economy and society, China Translation and Publishing Corporation, Beijing, Annexes 3.1, 3.2, 3.3 and 3.4, pp. 107-8, and Table 3.1, p. 52.

Running their assumptions through our system, we find that the United Nation's peak steel output per capita estimate is probably somewhat too low, although the implication that China will remain around its peak levels for a considerable period (at least $590 \mathrm{~kg}$ per capita from 2020 to 2040) seems reasonable. Also, given that the turning point of China's KCS is expected to be reached at a GDP per capita of US\$15 449 - a level that we can deduce the United Nations anticipates being achieved in 2032 - this roughly accords with their assumed timing of the peak in steel demand per capita. In short, the United Nation's steel projections seem rational enough in terms of overall shape and timing, but we would argue for a higher peak demand than that based on their other macroeconomic assumptions.

China has defined its own trajectory in a number of contexts to form a unique economic development path. Its future could also be distinctive if it were to define a path with respect to leapfrogging and consumer preferences that is out of the norm. 
In determining the likelihood that China will reach the peak level of its steel demand per capita in the time frame predicted by our naive projection, which of the upper or lower confidence intervals presents the most likely direction of error from the central tendency or whether China will or will not follow the path of Korea in terms of its long-term path of steel consumption, we need to leave aside empirics and trust judgment. The question is whether China's metal consumption will be influenced more by the consumer preference view or behave more according to the predictions of the leapfrogging view. It is a legitimate question as our model provides empirical evidence supporting the mutual inclusion of each of these views.

If, for example, the consumer preference dynamic operates so strongly that technological leapfrogging is hugely outweighed then there is a high probability that China will either prolong the period before it reaches the peak or it will increase the absolute peak level of steel demand per capita towards the upper confidence interval. Either or both possibilities will raise the chance that China might follow the metal intensity path of Korea.

On the other hand, if the leapfrogging phenomenon operates so strongly that it cancels out a larger than usual portion of the consumer preference dynamic, this will increase the probability that China could either shorten the period leading up to the turning point of the KCS or reduce the peak level of its steel intensity towards the lower confidence interval.

Figure 5.6 China's consumption of crude steel, 1978-2008 (million tonnes)

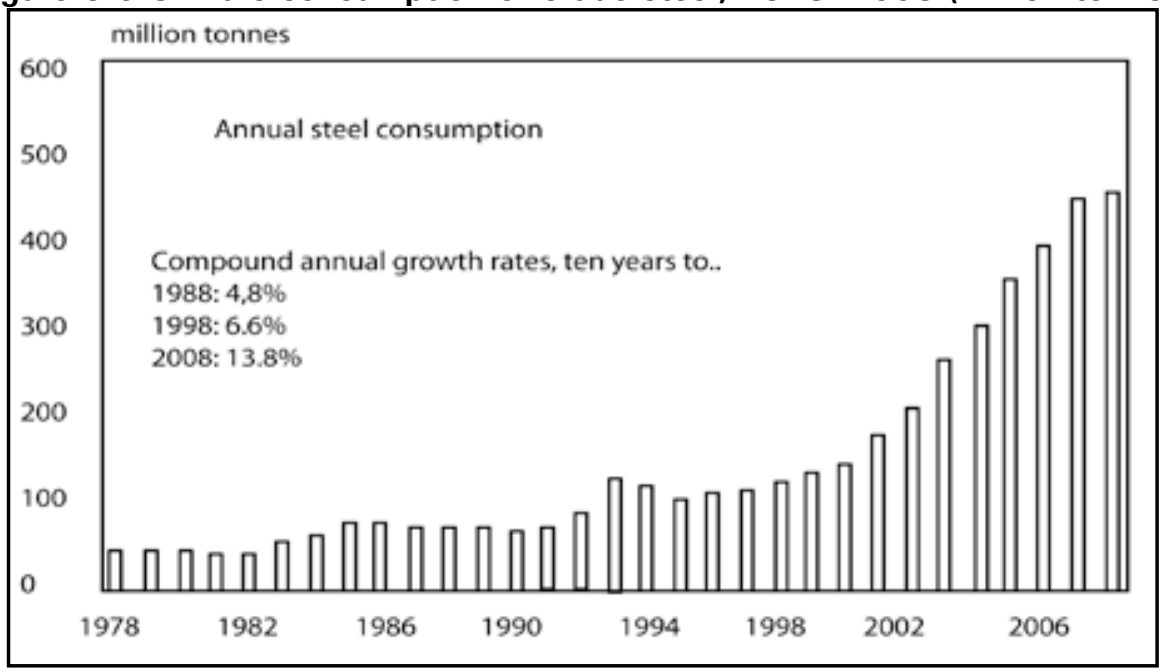

Source: National Bureau of Statistics (NBS) 2009, China Statistical Yearbook, China Statistics Press, Beijing; and author's calculations. 
According to its current level of per capita income, China is still at the mid phase of industrialisation characterised by the relatively high proportion of manufacturing in the total economy and a relatively high share of heavy industries in total industrial output (Chenery et al. 1986). A key feature of this phase of industrialisation is the pattern of extensive growth in which factor inputs - especially physical capital - play an important role. As a result, metal consumption has been accelerating sharply (Figure 5.6). China is far from reaching the saturation point of consumption of durable goods, as illustrated by its low automobile penetration ratio, which is just 5 per cent of the US level. That is especially true if one considers the existence of the vast and untapped rural consumer market. This suggests that there is ample room for increasing the consumption of durable goods in China with the associated rise in demand for metals. On this evidence, we can safely assume that the consumer preference dynamic will play a strong role in the coming decades.

On the other hand, looking beyond the immediate horizon, China is now approaching the end of a long period of extensive growth and will be relying more on technological change and productivity to expand economic activity (Wang 2007; He et al. 2007). China is entering a period in which its pattern of growth will be dictated not only by those fundamental forces that have been working in recent decades, but by the strategies that China has been compelled to adopt at this juncture of its development in order to face the challenges of global imbalances, climate change and the ageing society.

At the core of these strategies is a desire to alter its mode of industrialisation to take account of shifting comparative advantage and the fact that 'business as usual' will put immense pressure on the biosphere going forward. Structural changes will be assisted by altered incentives brought about through institutional changes such as financial system reform and the reform of the pricing system for resources and other factors of production (Huang and Tao 2010). The implementation of these new strategies will accelerate the pace of technological leapfrogging in China, moderating future increases in its metal consumption per capita.

While the desire for environmental amenity has a well-documented relationship to per capita income that is 'Kuznetsian' in shape, in China and elsewhere (Grossman and Krueger 1995; Bao and Peng 2006), no currently wealthy country had to deal with a global environmental backdrop as unpropitious as that of today. This implies that the imperative for China to pursue resourcesaving technological change in the future is greater than that of the individual economies in our historical sample. 
This short discussion highlights only that the consumer preference and leapfrogging dynamics will both be operating at high intensity in the coming decades in China. For now, it is not possible to prioritise one over the other.

Finally, we should sound a further cautionary note with respect to the projection. The objective of this study has been to define a range of potential outcomes for China's steel demand, not to produce a precise forecast. We believe that our confidence intervals are a reasonable approximation of the likely upside and downside risks to the central KCS tendency for China. Needless to say, if the underlying assumptions that generate the central tendency are over or underestimated, the accuracy of the projection will suffer.

\section{Conclusions}

This chapter had two aims. The first was to make a contribution to the theoretical field that related economic development to metal usage by constructing a new analytical framework. The second was to use those insights to shed light on China's future path of ferrous metal demand. The outcomes were as follows. First, a new concept - the Kuznets curve for steel-was formally identified. Second, the synthesis view of IU-that sees a role for both technological leapfrogging and evolving consumer preferences - was validated and updated for the per capita framework we prefer. To accommodate this test, a broader set of data was brought into the discussion than in previous studies, along with a more advanced econometric technique that allowed for the endogeneity of steel demand and income per capita and the heterogeneous nature of individual economic histories. Third, the turning point of China's own KCS was estimated at US\$15 449 GDP per capita - a point that on its post-1980 trajectory of 7 per cent compound growth China would reach during 2024. At that time, China's steel demand per capita is expected to be between 700 and $800 \mathrm{~kg}$, but closer to the latter. That is higher than the peak level reached in the United States, the CIS and Europe, but lower than the peaks seen in Japan, Korea and Taiwan. The eventual accuracy of this projection will depend on a great many factors, chief among them the pace of global technological change and the developing preferences of the Chinese consumer.

\section{References}

Bao, Q. and Peng, S. 2006, 'Economic growth and environmental pollution in China: a simultaneous estimation', Journal of World Economy, vol. 11, pp. $48-59$. 
Bruinsma, J. 2009, The resource outlook to 2050: by how much do land, water and crop yields need to increase by 2050?, Paper presented to the Expert Meeting on How to Feed the World in 2050, Food and Agriculture Organization of the United Nations, 24-26 June, Rome, $<\mathrm{ftp}$ ://ftp.fao.org/docrep/fao/012/ak97le/ak971e00.pdf >

Center for International Comparisons n.d., The Penn World Table, University of Pennsylvania, Philadelphia.

Chenery, H., Robinson, S. and Syrquin, M. 1986, Industrialisation and Growth: A comparative study, Oxford University Press for The World Bank, New York.

Etheridge, W. S. 1981, 'Demand for metals', Materials in Engineering, vol. 2 (March), pp. 131-40.

Food and Agriculture Organization (FAO) 2002, World Agriculture: Towards 2015/2030-summary report, Food and Agriculture Organization of the United Nations, Rome.

Food and Agriculture Organization (FAO) 2006, World Agriculture: Towards 2030/2050 - interim report, Food and Agriculture Organization of the United Nations, Rome.

Garnaut, R., Howes, S., Jotzo, F. and Sheehan, P. 2008,Emissions in the Platinum Age: the implications of rapid development for climate change mitigation, Garnaut Review Working Paper revised draft, 2 May 2008, $<$ www.garnautreview.org.au>

Garnaut, R., and Song, L. 2006, 'China's resources demand at the turning point,' (with Ross Garnaut), Chapter 14 in R. Garnaut and L. Song (eds), The Turning Point in China's Economic Development, Asia Pacific Press: Canberra, pp. 276-293.

Garnaut, R., Song, L. and Yao, Y. 2006, 'Impact and significance of SOE restructuring in China', The China Journal, no. 55 (January), pp. 35-66.

Grossman, G. and Krueger, A. 1995, 'Economic growth and environment', Quarterly Journal of Economics, vol. 110, no. 2, pp. 353-77.

Haggard, S. 1990, Pathways from the Periphery: The politics of growth in the newly industrialising economies, Cornell University Press, Ithaca, NY.

He, J., Li, S. and Polaski, S. 2007, 'China's economic prospects 2006-2020', Carnegie Papers, no. 83 (April). 
Huang, Y. and Tao, K. 2010, Causes and remedies of China's external imbalances, China Center for Economic Research Working Paper No. E2010002, 25 February 2010, Peking University, Beijing.

Hwang, K. H. and Tilton, J. E. 1990, 'Leapfrogging, consumer preferences, international trade and the intensity of metal use in less developed countries', Resources Policy, September, pp. 210-24.

International Iron and Steel Institute 1972,Projection 85: World steel demand, International Iron and Steel Institute, Brussels.

International Monetary Fund (IMF) 2005a, 'Will the oil market continue to be tight?', World Economic Outlook, April, International Monetary Fund, Washington, DC.

International Monetary Fund (IMF) 2005b, 'Global imbalances: a savings and investment perspective', World Economic Outlook, September, International Monetary Fund, Washington, DC.

Kuznets, S., 1955, 'Economic growth and income inequality', American Economic Review, vol. 45, no. 1, pp. 1-28.

Leontief, W., Koo, J., Nasar, S. and Sohn, I. 1983, The Future of Non-Fuel Minerals in the US and World Economy, Lexington Books, Lexington, Mass.

Lohani, P. R. and Tilton, J. E. 1993, 'A cross-section analysis of metal intensity of use in the less developed countries', Resources Policy, June, pp. 145-54.

McKay, H. 2008, Metal intensity in comparative historical perspective: China, North Asia, the United States \& Kuznets curve, Global Dynamic Systems Centre Working Paper 006, The Australian National University, Canberra.

McKay, H. and Song, L. 2009, 'Global implications of China as the manufacturing powerhouse', in R. Garnaut, L. Song and W. T. Woo (eds), China's New Place in the World in Crisis: Economic, geopolitical and environmental dimensions, ANU E Press and The Brookings Institution Press, Canberra and Washington, DC, pp. 261-302.

McKibbin, W. 2006, 'Global energy and environmental impacts of an expanding China" China and the World Economy vol. 14, no 4, pp. 38-56.

Maddison, A. 2003, The World Economy: Historical statistics, Organisation for Economic Cooperation and Development, Paris.

Maddison, A. 2010, Statistics on world population, GDP and per capita GDP, 1-2008AD, Internet file, <http://www.ggdc.net/maddison/articles/ruggles. $\operatorname{pdf}>$ 
Malenbaum, W. 1973, Material Requirements in the United States and Abroad in the Year 2000, University of Pennsylvania Press, Philadelphia.

Malenbaum, W. 1975, 'Law of demand for minerals', Proceedings of the Council of Economics, 104th Annual Meeting of the American Institute of Mining, Metallurgical and Petroleum Engineers, pp. 145-55.

Malenbaum, W. 1978, World Demand for Raw Materials in 1985 and 2000, McGraw-Hill, New York.

National Bureau of Statistics (NBS) various years, China Statistical Yearbook, China Statistics Press, Beijing.

Sohn, I. 2006, 'Long-term projections of non-fuel minerals: we were wrong, but why?', Resources Policy, vol. 30, pp. 259-84.

United Nations Development Programme (UNDP) 2010, China Human Development Report 2009/10. China and a sustainable future: towards a low carbon economy and society, China Translation and Publishing Corporation, Beijing.

Wang, X. 2007, Pattern and sustainability of China's economic growth towards 2020, Presented at the ACESA 2007 Conference: China's Conformity to the WTO: Progress and Challenges.

World Bank n.d., World Development Indicators, Online database, The World Bank, Washington, DC.

World Metal Statistics Yearbook, various issues, International Steel Association, Brussels, Belgium.

Zellner, A. 1962, 'An efficient method of estimating seemingly unrelated regressions and tests for aggregation bias', Journal of the American Statistical Association, vol. 57, pp. 348-68.

\section{Acknowledgments}

We thank Yixiao Zhou for her help with assembling the data used in the modelling exercise. 